\title{
Evoluções MOtoras e LINGUísticas de bebÊs COM ATRASO de DESENVOLVIMENTO NA PERSPECTIVA DE MÃES
}

\author{
M OTOR AND LANGUAGE DEVELOPMENT OF BABIES WITH DELAYED DEVELOPMENT \\ FROM THE MOTHERS' PERSPECTIVE
}

\author{
Tatiany HEKAVEI ${ }^{1}$ \\ Jáima Pinheiro de OLIVEIRA²
}

\begin{abstract}
RESU M O: o presenteestudo teve por objetivo investigar a evolução do desenvolvimento motor edelinguagem em bebês com atraso de desenvolvimento a partir da perspectiva materna. Participaram do estudo seis mães de bebês com atraso de desenvolvimento. A pesquisa foi real izada numa instituição com programa de intervenção precoce eem ambiente domiciliar. Foram feitas entrevistas com as mães, por meio de um roteiro semiestruturado. O modo de compreensão das mães, tanto do processo de desenvolvimento motor, quanto linguístico dos filhos, indicou uma evolução no desenvolvimento dessas crianças. Uma das provas disso, foi a forma como essas mães se referiram ao desenvolvimento das crianças, antes destas ingressarem no programa de intervenção precocee no momento atual. Conhecer evalorizar as percepções trazidas pel os cuidadores e particularmente pelas mães, implica em ampliar o entendimento dos seus saberes e práticas. Estes valores, por sua vez, podem ser utilizados no sentido de favorecer todo o processo de desenvolvimento infantil.
\end{abstract}

PALAV RAS-CH AVE: desenvolvimento da criança; desenvolvimento motor; desenvolvimento da linguagem; Educação especial.

\begin{abstract}
A BSTRACT : the aim of the present study was to investigate the evolution of motor and language development in developmentally delayed babies from the mother's perspective. Six mothers of developmentally delayed babies participated in the study. This study was conducted in an institution that had an early intervention program and in the home environment. Interviews with the mothers were conducted using a semi-structured questionnaire. The way the mothers understood both their children's processes of motor and language development was indicative of an evolution in these children's development. The ways these mothers reported on the development of the children beforethey entered the early intervention program and at present is evidence to this effect. To know and to value the perception that caretakers have about their children has to do with broadening their understanding and practices. Thesevalues, in turn, can beused towards assisting in the process of child development.
\end{abstract}

KEYWO RD S: child development; motor development; language development; Special education.

\section{INTRODUÇÃO}

Os trabalhos que envolvem percepções expressas pela população a respeito da saúdee da doença podem indicar maneiras peculiares de ouvir eol har seu próprio corpo (EISEMON; PATEL; SENZ, 1987; ZAHRAN; KOBAU; MORIARTY et al., 2005; WA RREN et al., 2004). E em muitos casos, essas percepções

\footnotetext{
${ }^{1}$ Bacharel em Fonoaudiologia pela Universidade Estadual do Centro-Oeste (UNICENTRO); Fonoaudióloga Clínica (Curitiba/ PR). E-mail: tatianyfono@hotmail.com

${ }^{2}$ Bacharel em Fonoaudiologia pela Faculdade de Filosofia e Ciência da Unesp, Campus de Marília/ SP; M estre em Educação Especial pela Universidade Federal de são Carlos (UFSCar/ SP); Docente do Departamento de Fonoaudiologia da Universidade Estadual do Centro-Oeste(UNICENTRO) - jaimafono@gmail.com
} 
são desconsideradas pelos profissi onais em suas relações com os pacientes, o que não é viável num trabal ho que tenha como meta a efetiva participação desse indivíduo no processo terapêutico.

No contexto da Educação Especial, os estudos de perspectivas maternas e de profissionais acerca de aspectos do desenvolvimento infantil são alvos de várias pesquisas (DARBAR; VASCONCELLOS; ARRUDA, 2008; SUNELAITIS; ARRUDA; MARCOM , 2007; PEREIRA-SILVA; DESSEN , 2007; OLIVEIRA; BRA GA, 2004; CARDOSO et al., 2003), muitas das quais têm o objetivo de aperfeiçoar as formas de intervenção com essa população e, principal mente, de orientar as mães acerca de como elas podem interferir de modo positivo nesse processo.

Sunelaitis, Arruda e Marcom (2007) realizaram um estudo sobre a percepção de mães acerca do processo de revelação do diagnóstico de Síndrome deDown (SD) eas repercussões disto no cotidiano familiar. A sautoras identificaram que o desconhecimento, as reações e atitudes das famílias constituem indicativos da necessidade de apoio profissional a essas mães e às famílias, que em algumas ocasi ões atémesmo escondem esse diagnóstico. Os dados revel aram que, às vezes, este diagnóstico é informado em circunstâncias e momentos inadequados e que algumas mães conhecem pouco sobre a síndrome, o que implica em expectativas de mel horia e avanços em curto prazo.

Pereira-Silva e Dessen (2007) investigaram os valores e as crenças de pais e professores sobreas práticas decuidados esocialização decrianças com esem Síndrome de Down. As autoras levaram em consideração os seguintes aspectos do desenvolvimento: desenvolvimento motor, escolarização, profissional ização, relações íntimas e expectativas quanto ao futuro. Os resultados mostraram diferenças nos valores ecrenças relatad os pel os genitores decrianças com esem síndromedeDown, especialmente no que se refere ao desenvolvimento motor do filho. As educadoras relataram mudanças no desempenho acadêmico das crianças, bem como em seus relacionamentos sociais. Enquanto as professoras do ensino especial esperam progressos nos resultados acadêmicos, em longo prazo, as professoras do ensino regular esperam resultados mais imediatos de suas crianças com desenvolvimento típico. Os dados indicaram semel hanças entre as crenças de pais e professoras, com foco para a crença de que o apoio e o envolvimento da família podem propiciar à criança com síndrome de Down os avanços necessários ao seu desenvolvimento.

No estudo de Oliveira e Braga (2004), as autoras tiveram o objetivo de ministrar um curso voltado para pais de crianças com alterações no desenvolvimento, a partir das concepções destes acerca desse processo. Foi observado que os pais, de modo geral, indicaram formas de estimulação do desenvolvimento dos filhos, demonstrando serem agentes facilitadores desse processo. O estudo enfatizou ainda a importância dos profissionais da saúde se responsabilizarem pelo fornecimento de práticas educativas voltadas para essa população, com o intuito de auxiliar tanto no atendimento como no desenvolvimento dos filhos. 
Cardoso et al . (2003) realizaram um estudo com o objetivo de verificar o conhecimento de mães eauxiliares do desenvolvimento infantil sobre o processo de desenvolvimento da linguagem em crianças de 0 a 24 meses de idade. As autoras fizeram aplicação de questionário e dentre os principais resultados destacaram as relações significativas referentes ao nível deescolaridadee o nível de conhecimento acerca do processo de desenvolvimento delinguagem das crianças nessa fai xa etária. As mães queindicaram maior conhecimento sobreo assunto tinham maior nível de escolaridade. Estes resultados contradizem o estudo deM ajnemer eRosenblatt(1994) que não encontraram relação entre nível deescolaridade, nível socioeconômico eas habilidades dos pais em relação aos principais aspectos do desenvolvimento infantil.

Em estudo recente com foco para a perspectiva materna acerca do desenvolvimento motor de crianças com paral isia cerebral, Darbar, Vasconcellose A rruda (2008) confrontaram relatos de pais com dados da avaliação motora com escala específica. Os autores verificaram que a maioria (70\%) dos pais subestimou o potencial motor dos filhos, embora a diferença motora (relatos versus escala) não tenha sido maior do que $20 \%$.

Rabuske, Oliveira eA rpini (2005) investigaram as concepções de mães em relação à criança e o seu desenvolvimento infantil, objetivando identificar a perspectiva dessas mães acerca desse processo. Além disso, o estudo objetivou também caracterizar as explicações atribuídas por elas aos comportamentos dos filhos. Participaram do estudo mães usuárias da rede pública de saúde e foram feitas entrevistas e analisadas por meio de seus conteúdos. Observou-se que as mães atribuíram aprendizagem e vulnerabilidade em relação à infância atual. Os comportamentos dos filhos foram avaliados como típicos e atípicos, a partir de comparações com outras crianças. Foi observado também que as mães atribuíram importância ao estabelecimento dos vínculos mãe-filhos e citaram as vivências cotidianas, decuidado, educação e convívio familiar, como importantes em todo o processo de desenvolvimento infantil, além de saberes científicos.

Sobre a influência materna no processo de desenvolvimento infantil, também é possível verificar uma vasta literatura (KRAUSS, 1997; KOLOBE; SPARLING; DANIELS, 2002; WILLIAMS; AIELLO, 2001; RAMEY; MULVIHIL; RAMEY, 1997). Dentro destecontexto, al guns trabal hos, por exemplo, deRodrigues eMiranda (2001) focam exclusivamente a estimulação da criança com necessidades especiais em casa vertendo tal foco para a mãe. Dessemodo, vếse quão relevantes tornam-se os estudos envolvendo as perspectivas dessa população.

De modo geral, os trabal hos que abordam a participação efetiva da família e a influência das primeiras interações no desenvolvimento de crianças com atraso, em especial da mãe, apontam para a necessidade de a intervenção envolver efetivamente a participação materna (POEHLMAN N; FIESE, 2001; SíGOLO, 1996). Tal indicação tem por finalidadea obtenção depadrões satisfatórios em todas as áreas do desenvolvimento e em especial de aspectos cognitivos, de linguagem e socialização. 
A partir do momento em que se prioriza a participação da família no desenvolvimento infantil, os programas de intervenção passam a ser vistos como possuidor de uma configuração, na qual as relações entre características biológicas das crianças, do ambientefísico e a interação entre elas e seus pais, são expostas e levadas em consideração durante as análises. Essa perspectiva ecológica (BRON FEN BREN NER, 1996) considera também o fato dessas interações ampliarem, quando as mesmas ocorrem satisfatoriamente, ou atenuarem o potencial infantil quando ocorrem de modo inadequado.

Confirma-se assim, que a participação dos pais depende diretamente do conhecimento que esses familiares têm, seja em relação ao desenvolvimento infantil ou ao processo terapêutico ao qual seus filhos estão submetidos (COELHO et al., 1998). Isso evidencia, por sua vez, a necessidade dos profissionais responsáveis pelo tratamento ou atendimento da criança delinearem propostas que tenham como objetivo facilitar a troca de conhecimentos, considerando fundamentalmente as perspectivas prévias familiares (OLIVEIRA; BRAGA, 2004; OLIVEIRA; FORM IGA; SANTIAGO, 2002).

Ainda, em relação a essa participação materna no desenvolvimento infantil, inúmeras pesquisas enfocando a interação entre mãe-criança também trouxeram grandes contribuições para os modelos tradicionais de intervenção precoce (GALLAGHER; 1998; BRAZELTON; CRAMER, 1992; BRAZELTON; LESTER, 1983) e, em alguns casos, permitem ainda que estes sejam revistos, no sentido de colocar a família em primeiro lugar, principalmente por causa dessa fundamental importância das primeiras relações infantis em todo o desenvolvimento da criança (BARNARD, 1997).

Dessa forma, conhecer e valorizar as percepções trazidas pelos cuidadores e particularmente pelas mães, implica em ampliar a compreensão por parte desta população dos val ores quea mesma possui eque podem ser utilizados no sentido de auxiliar em todo o processo de desenvolvimento. Além disso, os conhecimentos adquiridos pelos profissionais não podem ser tidos como únicose verdadeiros, pois essa conduta pode limitar fortemente seu trabalho na saúde coletiva, que requer uma compreensão ampla de processos educativos ligados às questões de saúde (CAM POS, 2003; 2000).

Levando em consideração esses aspectos, o presente estudo teve por objetivo investigar a evolução do desenvolvimento motor edelinguagem em bebês com atraso de desenvolvimento a partir da perspectiva materna.

\section{MATERIAIS E MÉTODOS}

O presenteestudo caracterizou-sepor ser do tipo exploratório, utilizandose como principal técnica de pesquisa a entrevista, propondo-se a uma análise qualitativa (GIL, 1991). Participaram do estudo 6 mães de bebês entre 0 e 3 anos de idade (cronológica) de ambos os sexos que apresentam atraso neuropsicomotor. 
Como critérios para inclusão na pesquisa, foram consideradas: participação voluntária na pesquisa, a existência de filhos com atraso neuropsicomotor e idade entre 0 e 3 anos e, principalmente a frequência destes num programa de intervenção precoce. Como critérios de exclusão foram considerados: a solicitação por parte das mães para interromper o estudo. A pesquisa foi desenvolvida numa Associação de Pais e Amigos de Excepcionais (APAE) de uma cidade do interior do Paraná/ PR enas resi dências das mães, após suas devidas autorizações.

Para a real ização do estudo foram utilizados: roteiro semiestruturado para entrevista com as mães e um Termo de Consentimento Livree Esclarecido. 0 projeto de pesquisa foi avaliado e aprovado pelo Comitêde Ética da Universidade Estadual do Centro-Oeste (UNICENTRO), sob o protocolo número 09844/2007, tendo, portanto, respaldo nas diretrizes e normas estabelecidas pela Resolução de 1996 do Consel ho Nacional de Saúde.

N um primeiro momento, foi feita uma visita à instituição eesclarecidos os objetivos do estudo para que a pesquisadora pudesse obter autorização para a realização deste. N um segundo momento, as mães foram selecionadas a partir dos critérios já estabelecidos e de acordo com dados em prontuários de crianças atendidas na instituição. Esses dados serviram também para obter informações acerca de dias e horários de atendimentos dessas crianças, a fim de iniciar os primeiros contatos com as mães.

Posteriormente, deu-se início às entrevistas com as mães. Estas foram agendadas de acordo com disponibilidades da pesquisadora e de cada mãe. As entrevistas ocorreram nos finais de semana, nas residências das mães. Tais entrevistas tiveram duração de trinta minutos, iniciando com a coleta de dados ausentes em prontuário e em seguida foram formuladas perguntas a respeito do desenvolvimento motor e linguístico das crianças, antes da entrada da criança na instituição eno momento atual. Os dados foram gravados em MP3/ 4(Player Music no Limit) e em seguida transcritos na íntegra para posterior análise.

A análise dedados col etados em prontuários buscou traçar o perfil dos bebês, a fim deconstatar o atraso em seu desenvolvimento. Em relação às entrevistas com as mães, estas também buscaram traçar os perfis das mesmas, bem como a percepção em relação ao desenvolvimento motor elinguístico dos filhos antes da entrada na instituição eno momento atual. A transcrição das entrevistas possi bilitou a análise destas por meio de categorização temática (SAMPIERI, 1998).

Destaca-se que na apresentação dos resultados, foram considerados apenas os trechos de fala relacionados com as categorias estabelecidas a partir dos objetivos do estudo, isto é, fal as das mães acerca do desenvolvimento motor e do desenvolvimento de linguagem dos bebês. Esses trechos foram separados por col chetes com reticências para indicar a interrupção da fal a da mãee as transcrições foram apresentadas em alguns momentos de modo literal e, em outros, com 
correções, em função da necessi dade detorná-las intel igíveis ao leitor. A inda sobre a apresentação das transcrições, em alguns momentos, as autoras utilizaram parênteses com descrições para explicação de vocabulários regionais. Exemplo: peças (cômodos da casa).

\section{Resultados e discussão}

1) Perfil das mães

\begin{tabular}{|l|l|l|l|l|}
\hline Mães & Idade & Nível de escolaridade & Gestação & Profissão \\
\hline M1 & 46 anos & Ensino fundamental incompleto & $8 .^{\text {a } \text { ordem }}$ & Do lar \\
\hline M2 & 14 anos & Ensino fundamental incompleto & $1 .^{\text {a } \text { ordem }}$ & Do lar \\
\hline M3 & 16 anos & Ensino fundamental incompleto & $2 .^{\text {a } \text { ordem }}$ & Camareira \\
\hline M4 & 28 anos & Ensino fundamental completo & $1 .^{\text {a } \text { ordem }}$ & Do lar \\
\hline M5 & 43 anos & Ensino fundamental incompleto & $4 .^{\text {a ordem }}$ & Do lar \\
\hline M6 & 32 anos & Ausência de escolaridade formal & $4 .^{\text {a } \text { ordem }}$ & Do lar \\
\hline
\end{tabular}

Quadro 1 - Caracterização das mães.

\section{2) Perfil dos filhos}

\begin{tabular}{|c|c|c|c|c|c|c|}
\hline Bebês & Idade & Sexo & Diagnóstico & Marcha & $\begin{array}{l}\text { Linguagem } \\
\text { oral }\end{array}$ & $\begin{array}{l}\text { Tempo de } \\
\text { acompanhamento } \\
\text { na instituição }\end{array}$ \\
\hline B1 & $\begin{array}{l}1 \text { ano e } 7 \\
\text { meses }\end{array}$ & $\mathrm{M}$ & $\begin{array}{l}\text { Atraso no } \\
\text { desenvolvimento } \\
\text { neuropsicomotor } \\
\text { (Síndrome de Down) }\end{array}$ & Ausente & Ausente & 1 ano e 4 meses \\
\hline B2 & 2 anos & $\mathrm{F}$ & $\begin{array}{l}\text { Atraso no } \\
\text { desenvolvimento } \\
\text { neuropsicomotor }\end{array}$ & Ausente & Ausente & 1 ano e 4 meses \\
\hline B3 & $\begin{array}{l}2 \text { anos e } 1 \\
\text { mês }\end{array}$ & $\mathrm{M}$ & $\begin{array}{l}\text { Atraso no } \\
\text { desenvolvimento } \\
\text { neuropsicomotor }\end{array}$ & Ausente & Ausente & 4 meses \\
\hline B4 & $\begin{array}{l}2 \text { anos e } 4 \\
\text { meses }\end{array}$ & $\mathrm{F}$ & $\begin{array}{l}\text { Atraso no } \\
\text { desenvolvimento } \\
\text { neuropsicomotor } \\
\text { associado à anomalia } \\
\text { craniofacial } \\
\text { congênita } \\
\text { (Fenda palatina) }\end{array}$ & Ausente & Ausente & 1 ano e 3 meses \\
\hline B5 & $\begin{array}{l}2 \text { anos e } 7 \\
\text { meses }\end{array}$ & $\mathrm{F}$ & $\begin{array}{l}\text { Atraso no } \\
\text { desenvolvimento } \\
\text { neuropsicomotor } \\
\text { (Síndrome de Down) }\end{array}$ & Presente & Ausente & 2 anos e 6 meses \\
\hline B6 & $\begin{array}{l}2 \text { anos e } \\
11 \text { meses }\end{array}$ & M & $\begin{array}{l}\text { Atraso no } \\
\text { desenvolvimento } \\
\text { neuropsicomotor }\end{array}$ & Ausente & Ausente & 2 anos \\
\hline
\end{tabular}

\section{Quadro 2 - Caracterização dos bebês.}


No Quadro 1 foi realizada a caracterização materna quanto à idade, nível de escolaridade, ordem de gestação e profissão.

Constatou-se que a idade das mães variou de 14 anos de idade a 46 anos. O nível deescolaridade das mesmas variou desdea ausência deescolaridade formal até o ensino fundamental completo, prevalecendo o nível de ensino fundamental incompleto (66,6\%). Quanto à ordem de gestação, esta variou de 1 a 8 gestações, resultando em uma média de 3. Com relação à profissão constatou-se que $83,3 \%$ da amostra foi designada como sendo "do lar".

Miranda, Resegue e Figueiras (2003) e Papalia, Olds e Feldman (2006) relatam em seus estudos que o baixo nível de escolaridade, profissão, ordem de gestação e idade materna podem ser considerados fatores de risco para o desenvolvimento infantil.

O nível de escolaridade dos pais está intimamente ligado à profissão que eles exercem e consequentemente à condição socioeconômi ca dos mesmos. É ela queinfluencia a moradia, saúdee educação do ser humano, influencia ai nda na rotina de toda família, pois em muitos casos há necessidade de que todos os integrantes de uma casa criem mai ores responsabilidades: os pais visando garantir o sustento da casa e as crianças, tendo a responsabilidade de cuidar de irmãos e irmãs mais jovens (PAPALIA; OLDS; FELDMAN , 2006).

No que se refere à idade materna, quando menor que 17 anos e maior que 40 durante a gestação também são denomi nados como fatores de risco para o desenvolvimento. Quando essa idade é superior aos 35 anos, Papalia, Olds e Feldman (2006) apontam que os riscos para ocorrer alterações são maiores, uma vez que há chances de aborto ou parto denatimorto, além de maior tendência para parto prematuro, crescimento fetal retardado, além de outras complicações ligadas ao nascimento ou a defeitos congênitos. Ressalta-se que mulheres mais velhas correm maiores riscos desofrer complicações duranteo parto, podendo até ocorrer óbito caso apresentem diabete, hipertensão ou hemorragia grave.

Ainda no que se refere ao perfil das mães, ressalta-se que este pode interferir direta ou indiretamente no modo como essas mães lidam ou concebem o desenvolvimento dos seus filhos, embora alguns estudos não tenham observado nenhuma relação dessa natureza (OLIVEIRA; BRA GA, 2004; MAJNEMER; ROSENBLATT, 1994).

Sobre a caracterização dos filhos, no Quadro 2 foram apresentados alguns dados a fim de traçar o perfil atual desses bebês, no que se refere à idade, sexo, diagnóstico, marcha, linguagem oral e tempo de acompanhamento na instituição. A idade dos bebês variou de 1 ano e 7 meses a 2 anos e 11 meses, resultando em uma média de 2 anos e 3 meses deidade, sendo $50 \%$ do sexo feminino e $50 \%$ do sexo masculino.

No que se refere ao diagnóstico dos bebês, observa-se no Quadro 2, que todos apresentaram atraso no desenvolvimento neuropsicomotor, sendo que 
dois (33,3\%) desses bebês têm Síndrome de Down. Houve também a presença de anomalia craniofacial congênita em $16,6 \%$ da amostra, manifestada pela presença de fenda palatina.

Em relação à marcha, 83,3\% dos bebês ainda não a adquiriram; destacase, que a idade menor entre os bebês é de 1 ano e 7 meses. Sobre a linguagem oral, $100 \%$ da amostra não a adquiriram, isto é, todos os bebês se comunicam por meios diferentes da linguagem oral. O tempo de frequência na instituição variou de 4 meses a 2 anos e 6 meses. Ainda, no Quadro 2, pôde-se observar que um dos bebês (16,6\%) recebeu assistência somente após os 18 meses de idade. Todos esses dados evidenciam o atraso de desenvolvimento na amostra (PAPALIA; OLDS; FELDMAN, 2006; MIRANDA; RESEGUE; FIGUEIRAS, 2003).

\section{3) Percepção das mães acerca do desenvolvimento motor e linguístico das Crianças}

\begin{tabular}{|c|c|c|}
\hline Mães & Desenvolvimento anterior & Desenvolvimento atual \\
\hline M1 & $\begin{array}{l}{[\ldots] \text { ele não tinha firmeza de segurar a }} \\
\text { cabeça né [...] era caidinho pra trais a } \\
\text { cabeça dele }[\ldots]\end{array}$ & $\begin{array}{l}{[\ldots] \text { tá demorando }[\ldots] \text { começou a engatinhar }[\ldots]} \\
\text { só que ele engatinha só arrastando o corpinho }[\ldots]\end{array}$ \\
\hline M2 & $\begin{array}{l}\text { [...]era nenezinho né, muito molinha demais } \\
\text { assim }[. . .] \text { me incomodava }[. . .] \text { eu dizia que } \\
\text { não era normal né }[\ldots]\end{array}$ & $\begin{array}{l}{[\ldots] \text { engatinhar }[\ldots] \text { apenas uns pouquinhos }[. . .]} \\
\text { mas ainda ela não vai de uma peça (cômodo da } \\
\text { casa) na outra [...] já fica de pé sozinha [...] } \\
\text { agora, tá firme, não tá mais molinha }[\ldots]\end{array}$ \\
\hline M3 & $\begin{array}{l}{[. .] \text { ele não pegava nada, nem parava }} \\
\text { sentado, só ficava deitado [...] nem firmava } \\
\text { a cabeça [...] não brincava com as } \\
\text { mãozinhas, ele não fazia nada [...] }\end{array}$ & $\begin{array}{l}\text { [...] esses dias ele conseguiu firmar a cabeça, tá } \\
\text { pedindo com as máos querendo pega alguma coisa } \\
{[\ldots] \text { hoje ele já consegue pega as coisa e já tá }} \\
\text { querendo engatinha [...]. }\end{array}$ \\
\hline M4 & $\begin{array}{l}\text { [...] ela não se movimentava [...] nem a } \\
\text { cabecinha ela levantava bem né, sentadinha } \\
\text { ela ficava [...] }\end{array}$ & $\begin{array}{l}{[\ldots] \text { ela não engatinha }[\ldots] \text { ela já firmar pra }} \\
\text { levanta sozinha, mais ela ainda não sabe né [...] } \\
\text { ela senta [...] já se levanta [...]tá atrasada devido } \\
\text { aos probleminha dela assim né, na parte motora } \\
{[\ldots] \text {. }}\end{array}$ \\
\hline M5 & $\begin{array}{l}\text { O desenvolvimento foi normal [...] ela } \\
\text { segurava a cabeça, ela sentou ligero [...] } \\
\text { ela demorou um pouco mais pra assim pra } \\
\text { andar, no mais não [...] }\end{array}$ & {$[\ldots]$ ta quase normal eu acho assim [...]. } \\
\hline M6 & $\begin{array}{l}{[\ldots] \text { ele quase num se mexia [...]era }} \\
\text { caidinho [...] má tudo mulinho [...] ele num } \\
\text { pegava um nada na mão [...] }\end{array}$ & $\begin{array}{l}\text { [...] agora ele já tá firme [...] hoje ele tá bem } \\
\text { esperto, pois o que a gente põe lá numa altura ele, } \\
\text { a gente quando olha ele tá aí no soalho [...] já } \\
\text { cunsegue pegar a mamadeira, sabe dá tchau pra } \\
\text { gente, sabe come já as coisa [...] }\end{array}$ \\
\hline
\end{tabular}

Quadro 3 - Percepção das mães acerca do desenvolvimento motor

De acordo com os relatos das mães expostos no Quadro 3, 83,3\% dos bebês apresentaram atraso no desenvolvimento motor anterior e esse atraso permanece no sentido estrito da aquisição da marcha. Por outro lado, é possível verificar nas falas das mães, uma perspectiva de evolução motora, indicada pelos termos: "tá firme", "não tá mais molinha", "hoje ele já consegue pega as coisa ejá tá querendo engatinhá", " já se levanta”, " hoje ele tá bem esperto". Esses dados vão de encontro com o estudo de Darbar, Vasconcellos e Arruda (2008) que 
confrontaram relatos de pais com dados da avaliação motora com escala específica, verificando quea maioria (70\%) dos pais subestimou o potencial motor dos filhos.

Alguns autores consideram aspectos relevantes do desenvolvimento motor, estritamenterelacionados à idade cronológica eà aquisição da marcha. É o caso de Jakubovicz (2002), Rotta ePedroso (2004), dentre outros. Para esses autores, de acordo com a faixa etária em que se encontram, todos estes bebês já deveriam ter controle cervical, habilidade de marcha, correr e chutar uma bola. Contudo, não foram constatadas tais aquisições em nenhuma destas crianças.

Embora tais habilidades já fossem esperadas para a idade dos bebês, é preciso considerar todos os agravantes em relação ao desenvolvimento destes bebês, caracterizados por fatores de risco para o desenvolvimento, relacionados tanto ao período pré, quanto peri natal. Nessesentido, não sepodecomparar o desenvolvimento dessas crianças com o daquelas que não foram afetadas por esses fatores.

No estudo de Peres (sem data), as mães decrianças com paralisia cerebral relataram uma preocupação maior em relação ao desenvolvimento motor, justificada em função da falta de dependência para realizar atividades de vida diária, tais como aprender a vestir-seea al imentar-sesozinho, assim como a mel hora do equilíbrio, coordenação e marcha. Normalmente a preocupação com as habilidades motoras pode se intensificar em função tanto das atividades diárias quanto pelo fato de a marcha ser um dos marcos no processo de desenvolvimento infantil (PAPALIA; OLDS; FELDMAN, 2006).

\begin{tabular}{|c|c|c|}
\hline Mães & Desenvolvimento anterior & Desenvolvimento atual \\
\hline M1 & $\begin{array}{l}{[\ldots] \text { demorou }[\ldots] \text { pra ele soltar os }} \\
\text { sonzinhos da voz, porque das outras } \\
\text { crianças, a minha foi mais adiantado né, } \\
\text { daí dele demorou mais [...] }\end{array}$ & $\begin{array}{l}\ldots] \text { ele não consegue falar, ele tem uns tipo de } \\
\text { som assim pra falar, mas ele não consegue }[\ldots] \text { tá } \\
\text { demorando }[\ldots] \text { ele pede, ele mostra com a } \\
\text { mãozinha assim [...] só assim }[\ldots]\end{array}$ \\
\hline M2 & $\begin{array}{l}{[. . .] \text { eu acho que tava atrasado }[. . .] \text { ela }} \\
\text { chorava bastante }[. . .] \text { eu tô vendo que } \\
\text { é mais atrasada né }[\ldots]\end{array}$ & $\begin{array}{l}{[\ldots] \text { é mais atrasada [...] você que tem que }} \\
\text { adivinhar o que ela quer né [...] porque ela chora } \\
\text { né [...] ela fala tipo pouca coisa né, a única coisa } \\
\text { o papá [...] só coisinha assim que ela fala [...] }\end{array}$ \\
\hline M3 & $\begin{array}{l}\text { [...] Ele não emitia sonzinhos, não tentava } \\
\text { falá nada [...] só ficava resmungando, não } \\
\text { fazia nada }[. . .]\end{array}$ & $\begin{array}{l}{[\ldots] \text { ele não tá falando ainda }[\ldots] \text { tá atrasado }[\ldots]} \\
\text { agora que ele tá fazendo som [...] antes ele nem } \\
\text { brincava com sonzinho, não fazia som [...] tá } \\
\text { tentando falar alguma coisa [...] hoje ele já faz } \\
\text { uma linguagem assim, grita, i aiaiai ele já fala } \\
{[\ldots] \text {. }}\end{array}$ \\
\hline M4 & $\begin{array}{l}\text { [...] Ela atrasou porque ela tinha fenda né } \\
\text { [...] até depois da cirurgia dela ela não } \\
\text { falava nada. Ela sempre resmungava assim } \\
\text { sabe, depois de um ano e meio que ela } \\
\text { começou assim a soltar bem, mas depois da } \\
\text { cirurgia que foi feita foi bem melhor [...] }\end{array}$ & $\begin{array}{l}{[\ldots] \text { eu acho que [...] como não escuta bem [...] }} \\
\text { não fala bem assim vávává essas coisa, pápápá ela } \\
\text { fala, mas assim, ainda mãe ela não fala }[. . .]\end{array}$ \\
\hline M5 & $\begin{array}{l}{[\ldots] \text { Quando era bebê né, bem bebezinho }} \\
\text { ela já resmungava normal, aqueles } \\
\text { resmungos de bebê }[\ldots]\end{array}$ & $\begin{array}{l}\text { [...] eu acho que tá atrasada a fala dela [...] as } \\
\text { primeiras palavrinhas ela já tá falando [...] ela } \\
\text { fala mamãe né, papai, papá, papá dá, mamá, estas } \\
\text { coisas assim ela fala [...] tem palavras assim que } \\
\text { ela não consegue falar [...] }\end{array}$ \\
\hline M6 & {$[\ldots]$ ele não resmungava quase $[\ldots]$} & $\begin{array}{l}{[\ldots] \text { tá demorando pa fala }[\ldots] \text { eu acho que ele tá }} \\
\text { meio atrasado }[\ldots] \text { ele começou a resmungar }[\ldots] \\
\text { tá começando agora }[\ldots] \text { fazer sonzinho }[\ldots] \text { com } \\
\text { quase três esse num fala }[\ldots]\end{array}$ \\
\hline
\end{tabular}

Quadro 4 - Percepção das mães acerca do desenvolvimento linguístico. 
De acordo com os relatos apresentados no Quadro 4, os bebês não apresentaram eainda não apresentam desenvolvimento linguístico esperado para sua idade, uma vez que nenhum apresenta emissões orais. Por outro lado, observase que $83,3 \%$ da amostra apresentam intenção comunicativa, manifestada pelo choro, expressões corporais e faciais, bal bucios e vocalizações. Somente em um destes bebês (M6) não é possível diferenciar tais intenções.

Dessa forma, observa-se que o atraso significativo em relação à linguagem, dá-se somente quanto aos aspectos estruturais. Esse atraso pode ser confirmado a partir dos estudos de Rotta e Pedroso (2004) que relatam que entre um ano e meio a dois anos de idade a criança já deve emitir em média 20 pal avras e entender cerca de 50. Complementam ainda que as crianças nessa faixa etária conseguem iniciar e manter diálogo. Porém, essas considerações se referem ao desenvolvimento da linguagem em crianças sem alterações ou riscos no seu desenvolvimento, diferentemente da população do presente estudo.

Sobre as alterações de linguagem, há duas formas principais das mesmas serem anal isadas, ou seja, uma al teração pode ser primária ou secundária, sendo que esta última remete-nos ao presente estudo. As alterações de linguagem de ordem secundária referem-se àquelas cujas manifestações advêm de um comprometimento maior em relação ao desenvolvimento da criança (MANDRÁ, 2008; BEFI-LOPES, 2003).

Ainda que haja controvérsia na literatura, o desenvolvimento da linguagem nesses casos parece seguir o padrão de desenvolvimento, em todo o seu processo. Por isso, prioriza-se a questão comunicativa em detrimento de aspectos formais da língua. Em alguns casos, é necessário intervir com formas alternativas e/ ou suplementares de comunicação (NUNES et al., 2003; VON TETZCHNER; MARTINSEN , 2002).

Constata-seainda a partir dos relatos maternos apresentados no Quadro 4, queas maiores aqui sições linguísticas dos bebês correspondem à faixa etária dos quatro meses, caracterizada pelo choro diferenciado do bebê, devido à fome, dor ou "manha". As vocal izações parecem estar relacionadas às sensações de bem estar, surgem os "jogos vocais" ou "autobal bucio", nos quais o bebê parece brincar com os sons que emite, embora os mesmos ainda não estejam voltados para a comunicação, já que o padrão do bal bucio éindiferenciado, havendo repetição da mesma sílaba (papapa, mamama).

Contudo, ressalta-se novamente que este desenvolvimento pode ser entendido de diferentes formas, pois alguns autores, dentre eles, Rodriguez e Miranda (2003) afirmam que nesse momento a linguagem já émanifestada a partir do olhar, do choro, sorriso, expressões corporais efaciais, sendo estas manifestações denominadas prélinguísticas. A lém disso, a partir deuma perspectiva pragmática, esses bebês possuem funções comunicativas instrumentais, reguladoras, interativas, pessoais, heurísticas, imaginativas, representativas e rituais (ZORZI, 2002). 
É preciso ressaltar ainda quea linguagem de crianças com Síndromede Down, presenteem dois dos bebês, ésempre referida na literatura como sendo mais evoluída do ponto de vista da compreensão, mas não da expressão e, portanto, a linguagem não-verbal exerce função significativa para essa população (LIMONGI, 2004).

Nesse sentido, as manifestações relatadas caracterizam a linguagem desses bebês, ou seja, é um período da aquisição, caracterizado pela intenção comunicativa, seja para satisfação de al guma necessidade ou para atrair a atenção do outro. Os relatos das mães indicam a necessidade de esclarecer sobre esses aspectos, ressal tando que a linguagem não pode ser considerada somente a partir de aspectos ligados às emissões orais.

\section{Considerações finais}

O modo de compreensão das mães, tanto do processo de desenvolvimento motor, quanto linguístico dos filhos, indicou uma evolução no desenvolvimento dessas crianças. Prova disso é a forma como se referem a esse desenvolvimento antes das crianças entrarem no programa de intervenção precoce e no momento atual.

Embora não se possa atribuir essa evolução totalmente em relação aos benefícios do programa, sem dúvida, muitos estudos têm indicado quea intervenção precoce contribui de modo significativo para o desenvolvimento da criança com atraso de desenvolvimento. E quando nesse programa a família éincluída de modo efetivo, os ganhos são ainda mais evidentes. Nesse sentido, o estudo da compreensão das mães acerca de aspectos do desenvolvimento dos filhos parece contribuir para essa evolução, quando essa concepção indica fatores positivos, como foi evidenciado nesse estudo.

Por outro lado, essa compreensão materna ainda está restrita aos grandes marcos do desenvolvimento infantil, ou seja, "o andar" e "o falar". Foi observada nos relatos das mães uma perspectiva de desenvolvimento relacionada a uma comparação do desenvolvimento dos filhos com crianças sem alterações nesse processo. Isso pode ser um grande indicativo da necessidade dessas mães serem aconsel hadas em rel ação às particularidades dessas crianças. N essesentido, o estudo com foco vertendo para as perspectivas maternas pôde contribuir para a identificação de importantes aspectos a serem abordados sobre o processo de desenvolvimento dos seus filhos. 


\section{ReferênCias}

BARNARD, K. E. Influencing parent-child interactions for children at risk. In: GURALNICK, M. J. The effectiven ess of early intervention. Baltimore: Paul H. Brookes Publishing Co, 1997. p. 249- 268.

BEFI-LOPES, D. M. Distúrbios do desenvolvimento da linguagem oral. In: ANDRADE, C. R. F.; MARCONDES, E. Fonoaudiologia em Pediatria. Editora Sarvier, 2003. p. 79-88.

BRAZELTON, T.B.; CRAMER, B.G. A s primeiras relações. São Paulo: MartinsFontes, 1992.

BRAZELTON, T. B; LESTER, B. M. N ew approaches to developmental screening of infants. New York: Elsevier Science Publishing, 1983.

BRONFENBREN NER, U. A ecologia do desenvolvimento humano: experimentos naturais e planejados. Porto A legre: Artes Médicas, 1996.

CAMPOS, C. E. A . O desafio da integral idadesegundo as perspectivas da vigilância da saúde e da saúde da família, Ciênc Saúde Col etiva, v. 8, n. 2, p. 569-584, 2003.

CAMPOS, G. W. S. Saúdepúbl ica esaú de coletiva: campo enúcleo desaberes epráticas. Campinas: Departamento demedicina preventiva esocial da FCM/ Unicamp, 2000. p. 1-30.

CARDOSO, R. M. et al. Conhecimento de mães e auxiliares de desenvolvimento infantil referentes ao desenvolvimento da linguagem de crianças de 0 a 24 meses, Revista Brasileira de Crescimento e D esenvol vimento H umano, v. 13, n. 2, p. 85-94, 2003.

COELHO, F. N. et al. O que os pais de recém-nascidos de alto risco conhecem sobreo desenvol vimento infantil. Temas Sobre D esenvol vimento, São Paulo, v.7, n.38, p.32-38, 1998.

DARBAR, I. A.; VASCON CELLOS, C. A. B.; ARRUDA, F. L. T. Comparação do parâmetro motor de crianças com paralisia cerebral: aplicação da escala GMFM versus entrevista com os pais. Temas sobre D esenvolvimento, São Paulo, v. 16, n. 91, p. 21-24, 2008.

EISEMON, T. O.; PATEL, V. L R.; SENZ, S. O. Uses of formal and informal knowledge in the comprehension of instructions for oral rehidratation therapy in Kenya. Soc. Sci. M ed., v.25, p. 1225-1234, 1987.

GALLAGHER, J. J. The family as a focus for intervention. In: MEISELS, S.J.; SHONKOFF, J.P. (Eds.). Handbook of early childhood intervention. Cambridge University Press, 1998. p. 540-559.

GIL, A. C. Como elaborar projetos de pesquisa. 3. ed. São Paulo: A tlas, 1991.

JAKUBOVICZ, R. A valiação, diagnóstico e tratamento em fonoaudiologia: psicomotricidade, deficiência de audição, atraso de linguagem simples e gagueira infantil. 2. ed. Rio de Janeiro: Revinter Ltda, 2002. 
KOLOBE, T.H.A.; SPARLING, J.W.; DANIELS, L.E. Family-centered intervention. In: CAMPBELL, S.K.; VANDER LINDEN, D.W.; PALISANO, R. J. (Eds.). Physical therapy for children. 2. ed. Philadelphia: W. B. Saunders Co., 2002. p.881-909.

KRAUSS, M. W. Two generations of family research in early intervention. In: GURALNICK, M. J. The effectiven ess of early intervention. Baltimore: Paul H. Brookes Publishing Co, 1997. p.611-624.

LIMONGI, S. C. O. A linguagem da SíndromedeDown, In: FERREIRA, L. P.; BEFILOPES, D. M.; LIMONGI, S. C. O. (Org.). Tratado de Fonoaudiologia. São Paulo: Editora Roca, 2004. p. 954-966.

MANDRÁ, P. P. Retardo delinguagem. Temas sobre D esenvolvimento, v.16, n. 91, p. 34-37, 2008.

MAJNEMER, A.; ROSENBLATT, B. Reability of parental recall of development milestones, Pediatr. N eurol., v.10, n. 4, p. 304-308, 1994.

MIRANDA, L. P.; RESEGUE, R.; FIGUEIRAS, A. M. C. A criança e o adolescente com problemas do desenvolvimento no ambulatório de pediatria. Jornal deP ediatria, suplemento 1, 2003.

NUNES, L. R. O. (Org). Favorecendo o desenvolvimento da comunicação em crianças e joven s com necessidades educacionais especiais. Rio de Janeiro: Dunya Editoria, 2003.

OLIVEIRA, J.P.;FORMIGA, C. K.M. R; SANTIAGO,A. M. Propostainterdisciplinar de estimulação do desenvolvimento infantil voltada para familiares de crianças atendidas em um setor neuropediátrico. In: GIA GHETI, C. M.; FERRARI, C. (Org.). Coletânea de Comunicações Científicas da V III Jornada de Fonoaudiologia da U nesp de M arília. 1 ed. Marília: Fundepe, 2002, p. 238-247.

OLIVEIRA, J. P.; BRA GA, T. M. S. Participação defamiliares em práticas educativas de equipes multidisciplinares. R evista de Extensão e P esquisa em Educação e Saúde, Marília Unesp Publicações, n. 2, p. 95-103, 2004.

PAPALIA, D. E.; OLDS, S. W.; FELDMAN, R. D. D esenvolvimento humano. 8. ed. Porto al egre: Artmed, 2006.

PEREIRA-SILVA, N. L.; DESSEN, M. A. Crianças com e sem síndrome de Down: valores e crenças de pais e professores. Rev. Bras. Educ. Espec. , Marília, v. 13, n. 3, 2007. Disponível em: http:/ / www.scielo.br/ rbee. A cesso em: 31 maio 2008.

PERES, R. C. N. C. Percepção de mães de crianças com paralisia cerebral sobre o desenvolvimento motor, cognitivo e social de seus filhos. Disponível em: http:/ / www.faeso.edu.br/ horus/ artigos. A cesso em: 30 abr. 2008.

POEH LMAN N, J.; FIESE, B. H. Parent-infant interaction as a mediator of the relation between neonatal risk status and 12-month cognitive development. Infant Behavior $\&$ D evelopment, v.24, p. 171-188, 2001. 
RABUSKE, M. M.; OLIVEIRA, D. S.; ARPINI, D. M. A criança e o desenvolvimento infantil na perspectiva de mães usuárias do serviço público de saúde. Estudos de Psicologia, Campinas, v. 22, n 3, p. 321-331, 2005.

RAMEY, C. T.; MULVIHIL, B. A.; RAMEY, S. L. Prevention: social and educactional factors and esarly intervention, in: Jacobson, J. M.; Mulixk, J. A. (Org.). M anual of diagnosis and professional practice in mental retardation. Washington: American Psychological Association, 1997. p. 215-227.

RODRIGUES, M. F. A.; MIRANDA, S. M. A estimulação da criança especial em casa entenda o queaconteceno sistema N ervoso da criança deficientee como vocêpode atuar sobre ele. São Paulo: Atheneu, 2003.

ROTTA, N. T.; PEDROSO, F. Desenvolvimento neurológico: avaliação evolutiva. Revista A mrigs, Porto A legre, p. 175-179, 2004.

SAMPIERI, R.H. M etodologia de la Investigación. México: Mc Graw Hill,1998.

SíGOLO, S.R.R.L. Trocas interativas entre mãe e criança com atraso de desenvolvimento: um sistema de análise. Temas em Psicologia, São Paulo, n. 1, p. 3343, 1996.

SUNELAITIS, R. C.; ARRUDA, D. C.; MARCOM, S. S. A repercussão de um diagnóstico de síndrome de Down no cotidiano familiar: perspectiva da mãe. A cta Paul. Enferm. , São Paulo, v. 20, n. 3, 2007. Disponível em: http:/ / www.scielo.br. A cesso em: 31 maio 2008.

VON TETZCHNER, S.; MARTINSEN, H. Introdução à comunicação aumentativa e alternativa. Porto: Porto Editorial, 2002.

ZAHRAN, H. S; KOBAU, R.; MORIARTY, D. G. ZACK et al. Centers for D isease Control and Prevention (CDC). H ealth-related quality of lifesurveillance-United States, 1993-2002, v. 54, p. 1-35, 2005.

ZORZI, J. L. A intervenção fonoau diológica nas alter ações de linguagem infantil. 2. ed. Rio de Janeiro: Revinter Ltda, 2002.

WARREN, J. R. et al. Characteristics as mediators in SES-heal th relationships. Soc Sci M ed, n. 59, p. 1367-78, 2004.

WILLIAMS, L.C.A.; AIELLO, A.L.R. 0 Inventário Portage 0 peracionalizado: intervenção com famílias. 1 ed. São Paulo: Memnon/ Fapesp, 2001.

Recebido em 10/ 06/ 2008

Reformulado em 15/ 11/ 2008

Aceito em 20/ 03/ 2009 